Article

\title{
Monolithic Wafer Scale Integration of Silicon Nanoribbon Sensors with CMOS for Lab-on-Chip Application
}

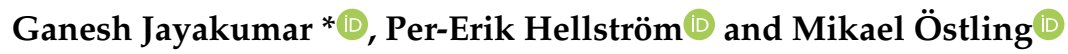 \\ KTH Royal Institute of Technology, Department of Electronics, School of Electrical Engineering and Computer \\ Science, 16440 Kista, Sweden; pereh@kth.se (P.-E.H.); ostling@kth.se (M.Ö.) \\ * Correspondence: ganeshj@kth.se
}

Received: 3 October 2018; Accepted: 23 October 2018; Published: 25 October 2018

check for updates

\begin{abstract}
Silicon ribbons (SiRi) have been well-established as highly sensitive transducers for biosensing applications thanks to their high surface to volume ratio. However, selective and multiplexed detection of biomarkers remains a challenge. Further, very few attempts have been made to integrate SiRi with complementary-metal-oxide-semiconductor (CMOS) circuits to form a complete lab-on-chip (LOC). Integration of SiRi with CMOS will facilitate real time detection of the output signal and provide a compact small sized LOC. Here, we propose a novel pixel based SiRi device monolithically integrated with CMOS field-effect-transistors (FET) for real-time selective multiplexed detection. The SiRi pixels are fabricated on a silicon-on-insulator wafer using a top-down method. Each pixel houses a control FET, fluid-gate (FG) and SiRi sensor. The pixel is controlled by simultaneously applying frontgate $\left(\mathrm{V}_{\mathrm{G}}\right)$ and backgate voltage $\left(\mathrm{V}_{\mathrm{BG}}\right)$. The liquid potential can be monitored using the FG. We report the transfer characteristics $\left(\mathrm{I}_{\mathrm{D}}-\mathrm{V}_{\mathrm{G}}\right)$ of $\mathrm{N}$ - and P-type SiRi pixels. Further, the $I_{D}-V_{G}$ characteristics of the SiRis are studied at different $V_{B G}$. The application of $V_{B G}$ to turn ON the SiRi modulates the subthreshold slope (SS) and threshold voltage $\left(\mathrm{V}_{\mathrm{TH}}\right)$ of the control FET. Particularly, N-type pixels cannot be turned OFF due to the control NFET operating in the strong inversion regime. This is due to large $\mathrm{V}_{\mathrm{BG}}(\geq 25 \mathrm{~V})$ application to turn $\mathrm{ON}$ the SiRi sensor. Conversely, the P-type SiRi sensors do not require large $V_{B G}$ to switch ON. Thus, P-type pixels exhibit excellent $\mathrm{I}_{\mathrm{ON}} / \mathrm{I}_{\mathrm{OFF}} \geq 10^{6}$, SS of $70-80 \mathrm{mV} / \mathrm{dec}$ and $\mathrm{V}_{\mathrm{TH}}$ of $0.5 \mathrm{~V}$. These promising results will empower the large-scale cost-efficient production of SiRi based LOC sensors.
\end{abstract}

Keywords: silicon ribbon pixel; silicon ribbon biosensor; lab-on-chip; SiRi CMOS integration; selective multiplexed detection; SiRi frontgate mode; SiRi backgate mode

\section{Introduction}

Silicon ribbon (SiRi) field-effect-transistors (FETs) have been widely recognized as efficient standalone prostate specific antigen (PSA) cancer marker, DNA, virus and $\mathrm{pH}$ sensors [1-9]. The small size, high surface to volume ratio, electrical read-out and a dimension that is comparable to the target of interest make SiRi-FETs an excellent contender for label-free $\mathrm{pH}$ and bio detection [1-9]. Table 1 summarizes some of the most important works employing SiRi sensor for the detection of $\mathrm{pH}$ or bio targets.

The sensing mechanism of the SiRi-FET is based on the principle of detection of surface charge (Figure 1). Initially, the current flowing through the SiRi is measured without any DNA hybridization and its threshold voltage is noted $\left(\mathrm{V}_{\text {th1 }}\right)$ (Figure 1a). Later, the surface of the SiRi is functionalized with the receptors and target of interest such as a double stranded DNA. Then, the current flowing through the SiRi is re-measured. The addition of DNA molecule on the surface and the resulting 
hybridization process causes a change in the surface charge density $\left(\mathrm{Q}_{\text {hybrid }}\right)$. As a result, it changes the threshold voltage of the $\operatorname{SiRi}\left(\mathrm{V}_{\text {th2 }}\right)$ (Figure $\left.1 b\right)$. By noting the difference in the threshold voltages $\left(\Delta \mathrm{V}_{\text {th hybridization }}=\mathrm{V}_{\text {th2 }}-\mathrm{V}_{\text {th1 } 1}\right)$ before and after DNA addition, the amount of additional charge $\left(\mathrm{N}_{\text {hybrid }}\right)$ resulting from the target molecule of interest can be estimated using Equation (1) [10].

$$
\mathrm{N}_{\text {hybrid }}=\mathrm{Q}_{\text {hybrid }} / \mathrm{q}=-\Delta \mathrm{V}_{\text {th }}\left(\varepsilon_{0} \varepsilon_{\mathrm{r}}\right) /\left(\mathrm{qt} \mathrm{tox}_{\mathrm{ox}}\right.
$$

Table 1. A summary of some of the most important works employing silicon ribbon (SiRi) sensor for the detection of $\mathrm{pH}$ or bio targets. The distinction is made based on fabrication method (top-down (TD) versus bottom-up (BU)), substrate type (Bulk Si versus silicon-on-insulator (SOI)) and type of sensor. Further, the application and complementary-metal-oxide-semiconductor (CMOS) integration feature are also considered.

\begin{tabular}{cccc}
\hline Reference & $\begin{array}{c}\text { Fabrication Method, } \\
\text { Substrate, Device Type }\end{array}$ & CMOS Integration & Application \\
\hline Zhang et al. [1] & TD, SOI, SiRi & No & Dengue virus (DEN-2) \\
Lee et al. [2] & TD, SOI, SiRi & No & $\mathrm{pH}$ \\
Park et al. [3] & TD, SOI, SiRi & No & $\mathrm{pH}$ \\
Yoo et al. [4] & TD, SOI, SiRi & No & $\mathrm{pH}$ \\
Nguyen et al. [5] & BU, Bulk, SiNN-FET & No & DNA \\
Kim et al. [6] & TD, SOI, SiRi & No & PSA cancer marker \\
Chaing et al. [7] & TD, SOI, SiRi & No & H5N2 virus \\
Chen et al. [8] & TD, SOI, SiRi & No & $\mathrm{pH}$ \\
Tarasov et al. [9] & TD, SOI, SiRi & No & pH, ions \\
\hline
\end{tabular}

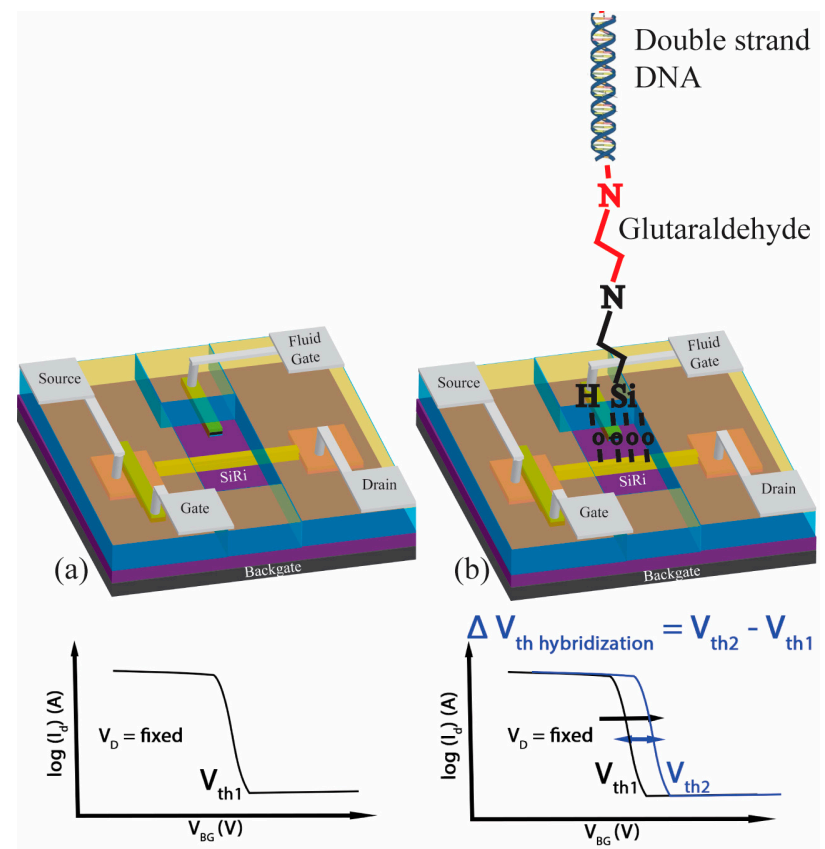

Figure 1. A schematic depicting the working mechanism of a silicon ribbon (SiRi) sensor. (a) The threshold voltage $\left(\mathrm{V}_{\mathrm{th} 1}\right)$ of the SiRi sensor is measured before bio molecule addition. (b) The target double strand DNA molecule is added on the surface where it undergoes hybridization process. As a result, the surface charge on the SiRi changes. The threshold voltage of the SiRi is measured again $\left(V_{\text {th2 } 2}\right)$. By noting the change in the threshold voltage $\left(V_{t h 2}-V_{t h 1}\right)$, the added charge on the surface can be estimated.

In particular, the SiRi-FETs described in this work can be functionalized using the process shown by Nguyen et al. [5] and Jayakumar et al. [11]. The first step in the DNA probe covalent grafting process is silanization. In this step, the sensor surface is functionalized with single strand DNA using 
an organosilane such as (3-Aminopropyl)triethoxysilane (APTES) [5]. Later, the sensor can be used for the hybridization detection of target DNA that is complementary to the probe DNA [11]. At the same step, to verify the selectivity of the sensor, its surface is exposed to non-complementary DNA and saline buffer solution that is free of complementary DNA [11]. A well-behaved SiRi sensor is expected to not respond to the non-complementary DNA or the salt crystallization after drying and only exhibit $\mathrm{V}_{\mathrm{TH}}$ shifts because of the target complementary DNA [11]. Indeed, the sensing mechanism employed by works listed in Table 1 relies on the conductance changes in the SiRi channel. However, as shown in our previous work, during the electrical characterization of the sensor (after silanization, grafting and hybridization steps), the current ratio ( $\left.\mathrm{I}_{\mathrm{ON}} / \mathrm{I}_{\mathrm{OFF}}\right)$ and subthreshold slope (SS) of the SiRi-FET almost remain constant. The transfer characteristics of the sensor only translate as shift in the threshold voltage [11] (Figure 1). This method of detection ensures that there is no fluctuation of the drain current during sensing and the field effect electrostatic coupling occurs between the charges on the SiRi surface and the channel [11]. The biodetection efficiency of such a DNA hybridization detection process is characterized by the sensitivity parameter, which is defined as the threshold voltage shift $\left(V_{\text {th2 }}-V_{\text {th1 }}\right)$ after hybridization [11].

The attractive benefits of SiRi sensors can be further extended to selective target detection, multi-target detection, and synchronous real-time read-out by integrating them with complementary metal oxide semiconductor (CMOS) field-effect transistors (FETs) and circuits [12]. Furthermore, the integration of SiRi sensors with CMOS read-out circuits establishes a platform for the realization of a complete lab-on-chip (LOC) sensor. However, as can be seen in Table 1, even though many researchers have successfully used the standalone SiRi sensor for detection of $\mathrm{pH}$ and bio-targets, none of the works address the monolithic integration of SiRi with CMOS. The goal of this paper is to establish one such platform. We achieve the SiRi CMOS integration by employing a pixel-based LOC architecture. The pixel-based SiRi LOC design is akin to the CMOS image sensor pixel design [13].

Figure 2 shows the proposed scalable sequential read-out scheme to integrate SiRi sensors with CMOS. The details of the circuits and the layout are described elsewhere [14]. Here, we highlight the salient features relevant to SiRi integration. In the pixel based integration scheme, each $\mathrm{SiRi}$ is connected to an on-chip fluid gate and a control transistor forming a SiRi pixel [14]. " $\mathrm{N} \times \mathrm{N}$ " matrix of such pixels can be addressed using N-bit vertical and horizontal shift register circuits, respectively. In this design, the transistor is configured as a switch to particularly control a specific row or column. Especially, the on-chip fluid gate is integrated in the design to monitor the potential in the liquid environment. The advantage of such a design is that the output current of the pixel array could further be monolithically connected to amplifiers for signal amplitude magnification, band pass filters for reducing the noise or allowing only a certain range of the signal and other read-out circuits such as a trans-impedance amplifiers to convert current to voltage output [12].

To avail such desirable benefits of CMOS integration, the manufacturing scheme employed for the realization of SiRi pixel sensor also has to be CMOS compatible. Traditionally, there are two methods to manufacture SiRi sensors: (1) bottom-up (BU); and (2) top-down (TD) [15-17]. In the BU method, the SiRi sensors are realized by using molecular pre-cursors. For example a silicon nanonet field effect transistor (SiNN-FET) can be manufactured on a bulk Si wafer using the BU method $[5,18]$. On the contrary, in the TD method, SiRi sensors are commonly realized on a silicon-on-insulator (SOI) substrate using the well-established lithography and patterning techniques [2-4,6-9,19]. It is particularly challenging to transfer the bottom-up grown nanonets on to a CMOS wafer and continue processing due to the tangling of the grown wires, difficulty in alignment and manual errors [20]. Further, in the bottom-up method, the probability of introducing contaminants on to the wafer is very high $[18,20]$. It also demands the usage of specialized alignment methods that tend to be time consuming $[18,20]$. In comparison, the top down method is CMOS compatible and allows for the low-cost co-integration of SiRi sensors with metal-oxide-semiconductor field-effect transistors (MOSFETs) and circuits [14-17]. 
Therefore, in this article, we utilize the fully CMOS compatible top-down method to fabricate the SiRi pixel sensors on wafer scale. Then, we show the first electrical results of the pixel design for both $\mathrm{N}$ - and P-type SiRi pixels. Single SiRi sensors of dimensions width $\mathrm{W}=1 \mu \mathrm{m}$ and length $\mathrm{L}=1 \mu \mathrm{m}$ were connected to $\mathrm{N}$ - and P-type CMOS transistors ( $\mathrm{W}=4 \mu \mathrm{m}$ and $\mathrm{L}=1 \mu \mathrm{m}$ ) to fully exploit the monolithic integration of SiRi with CMOS transistors. The SiRi pixel can be operated in two different modes: (a) the frontgate mode; and (b) the backgate mode. In the frontgate mode, the pixel is turned ON or OFF by applying a frontgate voltage to the $\mathrm{N}$ - and P-type transistors, while the backgate bias is fixed. In the backgate mode, the pixel is turned ON or OFF by applying a backgate voltage to the substrate, while the frontgate bias of the $\mathrm{N}$ - and P-type transistors is fixed. Both modes of operation validate the concept of establishing control of individual SiRi pixel modules in a matrix of sensors. Indeed, these promising results will empower the large-scale cost efficient production of compact label-free SiRi based lab-on-chip (LOC) sensors.

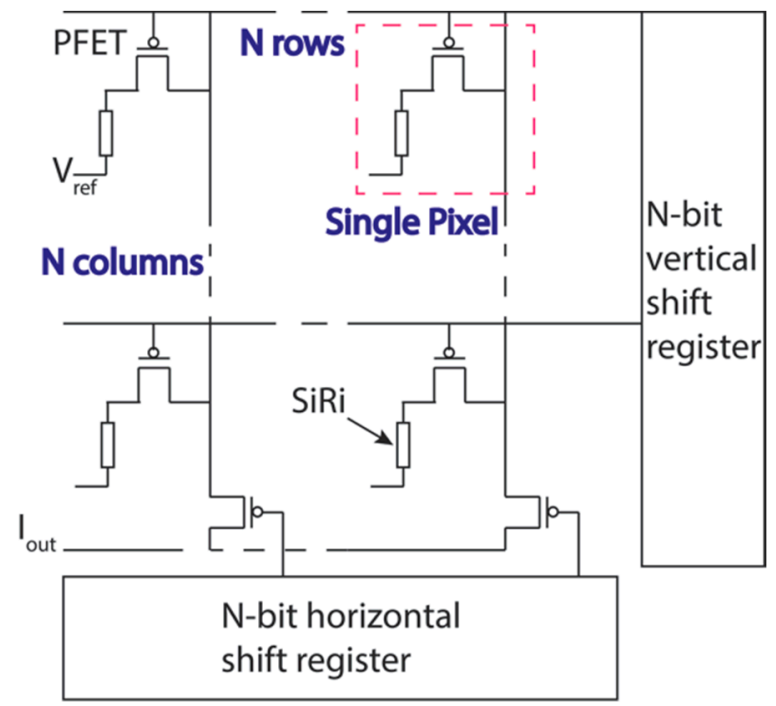

Figure 2. Circuit diagram of SiRi pixel based lab-on-chip (LOC). Each SiRi is connected to an on-chip fluid gate and a control transistor forming a SiRi pixel [14]. "N $\times$ N" matrix of such pixels can be addressed using N-bit vertical and horizontal shift register circuits, respectively.

\section{Materials and Methods}

The important steps in the fabrication of the SiRi pixel sensor are shown in Figure 3. The SiRi pixel sensors were fabricated on boron doped $\left(1 \times 10^{15} \mathrm{~cm}^{-3}\right) 4^{\prime \prime}(100 \mathrm{~mm})$ SOI wafer. A $145 \mathrm{~nm}$ buried oxide layer (BOX) separates the top $55 \mathrm{~nm}$ crystalline silicon (c-Si) device layer from the substrate. The c-Si device layer was thermally oxidized at $1000^{\circ} \mathrm{C}$ and thinned down to $20 \mathrm{~nm}$ (Figure 3A).

Then, $40 \mathrm{~nm} \mathrm{SiO}_{2}$ hard mask was deposited by plasma enhanced chemical vapor deposition (PECVD) at $400{ }^{\circ} \mathrm{C}$ (Figure 3B). The SiRi pattern and active region was defined on the $\mathrm{SiO}_{2}$ surface using conventional I-line lithography. Using a resist mask the $\mathrm{SiO}_{2}$ was selectively etched towards c-Si in $\mathrm{CHF}_{3} / \mathrm{CF}_{4} / \mathrm{O}_{2}$ plasma (Figure 3C). Then, the $20 \mathrm{~nm}$ c-Si device layer was etched using $\mathrm{SiO}_{2}$ as mask in $\mathrm{Cl}_{2} / \mathrm{HBr} / \mathrm{O}_{2}$ plasma (Figure 3D). The final dimension of the SiRi sensor is $1 \mu \mathrm{m} \times 1 \mu \mathrm{m} \times 20 \mathrm{~nm}$ $(\mathrm{L} \times \mathrm{W} \times \mathrm{H})$. Next, a diluted HF spray etch was employed to strip the $\mathrm{SiO}_{2}$ on top of source/drain pads which recessed the BOX to $140 \mathrm{~nm}$. Later, the active region of the SiRi pixel was thermally oxidized at $800{ }^{\circ} \mathrm{C}$ to form $5 \mathrm{~nm} \mathrm{SiO}_{2}$. This $5 \mathrm{~nm} \mathrm{SiO}$ forms the gate dielectric material for the control transistor in the SiRi pixel. This step was followed by $10 \mathrm{~nm}$ physical vapor deposition (PVD) of TiN gate metal, low-pressure chemical vapor deposition (LPCVD) of $100 \mathrm{~nm} \mathrm{n}{ }^{+}$polysilicon and PECVD deposition of $40 \mathrm{~nm} \mathrm{SiO}_{2}$ hard mask.

The transistor gate and on-chip fluid gate were patterned using I-line lithography and without breaking vacuum in the reactive ion etching (RIE) chamber the $\mathrm{n}^{+}$poly silicon/ TiN stack was 
selectively etched towards underlying c-Si active region using $\mathrm{Cl}_{2} / \mathrm{HBr} / \mathrm{O}_{2}$ and $\mathrm{BCl}_{3} / \mathrm{Cl}_{2}$ plasma, respectively (Figure 3E). Next, using a resist mask that covers the SiRi region, the active regions of the SiRi pixel was implanted. To form N-type SiRi pixels, the source/drain regions was doped with $\mathrm{As}^{+}$, whereas, to form P-type SiRi pixels, the source/drain regions were doped with $\mathrm{BF}_{2}$ (Figure 3F).

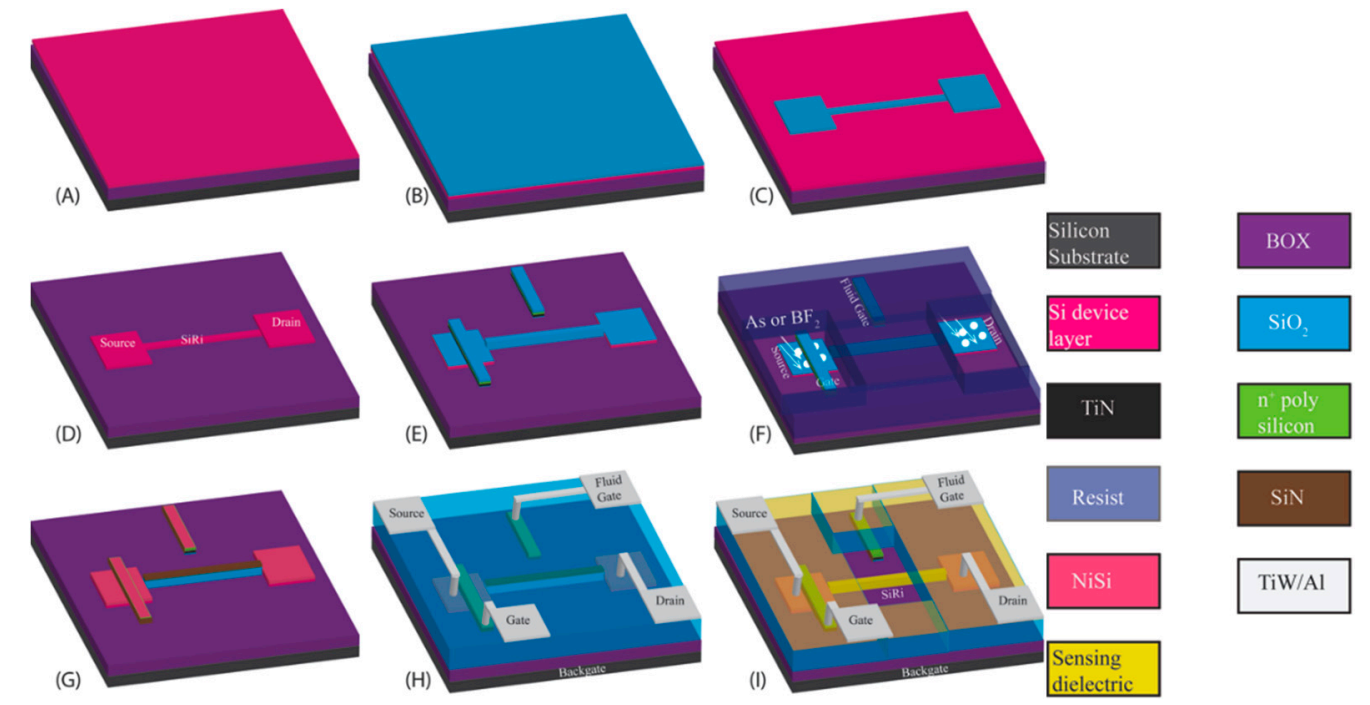

Figure 3. Schematic of the process steps employed in the manufacturing of the SiRi pixel sensor: (A) SOI wafer starting substrate; (B) deposition of $40 \mathrm{~nm} \mathrm{SiO} 2$ hard mask; (C) lithography and $\mathrm{RIE}$ of $\mathrm{SiO}_{2}$ hard mask to define the contact pads of the control transistor and SiRi channel; (D) reactive ion etching (RIE) of the crystalline silicon (c-Si) device layer using $\mathrm{SiO}_{2}$ mask and transfer of the pattern to c-Si device layer; (E) thermal gate-oxide growth, TiN gate metal and $\mathrm{n}^{+}$polysilicon deposition and patterning to define the frontgate of the transistor and fluid gate of the SiRi pixel; $(\mathbf{F})$ As or $\mathrm{BF}_{2}$ ion-implantation step using resist mask to form N-metal-oxide-semiconductor (NMOS) and P-metal-oxide-semiconductor (PMOS) pixels respectively; $(\mathrm{G})$ after dopant activation and $\mathrm{SiO}_{2} / \mathrm{SiN}$ spacer formation along the gate sidewall, NiSi ohmic contact formation; $(\mathbf{H})$ contact hole definition and TiW/Al metal patterning; and (I) etching pathways to access the SiRi test site using lithography mask and RIE etching. Later, a $10 \mathrm{~nm}$ atomic layer deposition (ALD) $\mathrm{SiO}_{2}$ passivation oxide that also behaves as sensing dielectric is deposited.

In the cases of $\mathrm{N}$ and P SiRi pixels, the dose of $1 \times 10^{15} \mathrm{~cm}^{-3}$ and energy $10 \mathrm{keV}$ was optimized based on iterations in semiconductor simulation software SRIM (2013 version) developed by James F. Ziegler, USA. The $40 \mathrm{~nm} \mathrm{SiO}$ gate etch mask and thin layer of $\mathrm{SiO}_{2}$ gate dielectric material was preserved during the implantation to avoid surface damage and $7^{\circ}$ tilt angle was opted to avoid channeling. After resist stripping, a thin layer of $10 \mathrm{~nm} \mathrm{SiO}$ was deposited by atomic layer deposition (ALD) followed by deposition of an additional $60 \mathrm{~nm} \mathrm{SiN}$. The $\mathrm{SiO}_{2} / \mathrm{SiN}$ stack was patterned using I-line lithography and etched everywhere except on-top of the $\mathrm{SiRi}$. This $\mathrm{SiO}_{2} / \mathrm{SiN}$ stack is later used as a mask during the salicide process step to prevent silicidation of the SiRi.

After the $\mathrm{SiO}_{2} / \mathrm{SiN}$ patterning, a rapid thermal annealing (RTA) step followed at $100{ }^{\circ} \mathrm{C}$ for $10 \mathrm{~s}$ to activate the dopants. Next, $\sim 40 \mathrm{~nm}$ gate $\mathrm{SiO}_{2}$ mask and $\sim 5 \mathrm{~nm}$ thermal oxide $/ 10 \mathrm{~nm} \mathrm{SiO}$ lying on top of the source/drain region is cleared using diluted HF spray etch. A $5 \mathrm{~nm} \mathrm{Ni}$ was deposited using PVD and annealed at $450{ }^{\circ} \mathrm{C}$ for $30 \mathrm{~s}$ to form low resistance ohmic source/drain and gate contacts (Figure 3G). The unreacted $\mathrm{Ni}$ was stripped in $\mathrm{H}_{2} \mathrm{SO}_{4}: \mathrm{H}_{2} \mathrm{O}_{2}$ (3:1) mixture. Then, $400 \mathrm{~nm} \mathrm{PECVD} \mathrm{SiO}_{2}$ was deposited, patterned using I-line lithography and RIE was done in $\mathrm{CHF}_{3} / \mathrm{CF}_{4} / \mathrm{O}_{2}$ plasma to define contact hole for the SiRi pixel. After metallization using PVD $100 \mathrm{~nm}$ TiW lining layer and $500 \mathrm{~nm} \mathrm{Al}$ layer, patterning and $\mathrm{SF}_{6} / \mathrm{BCl}_{3} / \mathrm{Cl}_{2} \mathrm{RIE}$ etching (Figure $3 \mathrm{H}$ ), $100 \mathrm{~nm}$ PECVD passivation oxide layer was deposited to protect the metal lines and the transistor. 
The top-view scanning electron microscope (SEM) image of a typical single SiRi pixel device after the metallization step but prior to opening access to SiRi test site is shown in Figure 4A. At this stage, the $500 \mathrm{~nm} \mathrm{SiO}_{2}$ is still lying on-top of the $\mathrm{SiRi}$ along with the $10 \mathrm{~nm} \mathrm{SiO} 2 / 60 \mathrm{~nm} \mathrm{SiN}$ stack that was deposited to mask silicidation process. The sensing area of the SiRi channel was exposed by using a resist mask, I-line lithography step and selective $\mathrm{RIE}$ of $\sim 570 \mathrm{~nm}$ dielectric in $\mathrm{CHF}_{3} / \mathrm{CF}_{4} / \mathrm{O}_{2}$ plasma. Then, $10 \mathrm{~nm} \mathrm{ALD} \mathrm{SiO} 2$ was deposited at $350{ }^{\circ} \mathrm{C}$ on top of the SiRi sensor (Figure $3 \mathrm{I}$ ).

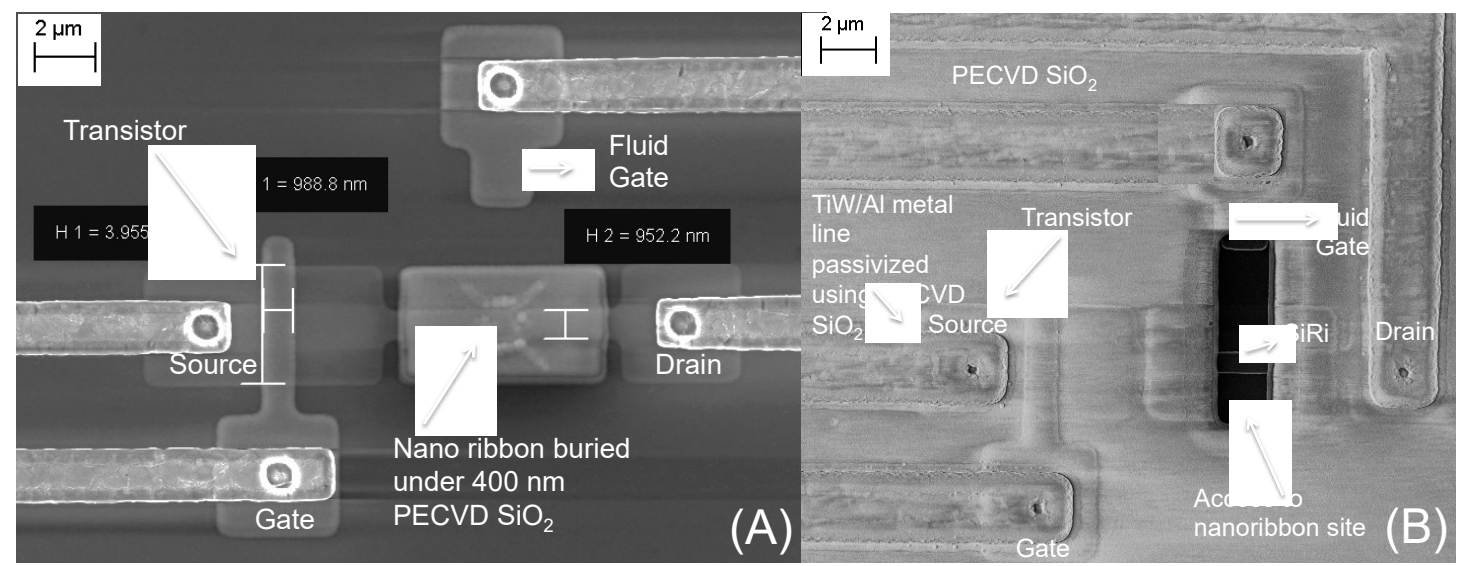

Figure 4. Top view scanning electron microscope (SEM) image of a single SiRi pixel showing the control FET, fluid gate and SiRi sensor: (A) before opening access to the SiRi test site; and (B) after opening access to the SiRi test site.

The $\mathrm{ALD} \mathrm{SiO}_{2}$ will behave as the passivation layer on top of the sensor as well as act as the sensing dielectric during the bio functionalization experiments. Figure 4B shows the top-view SEM image of a SiRi pixel after opening access to SiRi test site. To probe the SiRi pixels, the $100 \mathrm{~nm}$ passivation oxide lying on-top of the bondpads was etched using $\mathrm{CHF}_{3} / \mathrm{CF}_{4} / \mathrm{O}_{2}$ plasma. Finally, a forming gas anneal was done at $400{ }^{\circ} \mathrm{C}$ and marks the completion of the entire fabrication process.

\section{Electrical Characterization}

The setup shown in Figure 3I was used for the electrical evaluation of the SiRi pixel sensors prior to functionalization. A Cascade 12,000 semi-automatic wafer prober (Cascade Microtech, Beaverton, OR, USA) that was externally connected to a Keithley 4200-SCS parameter analyzer (Tektronix, Inc., Beaverton, OR, USA) was used to perform direct current (DC) electrical measurements. It also facilitated full-scale wafer mapping. In the pixel module, the source terminal of the transistor is connected to the column selection line while the drain terminal of the transistor is connected to the SiRi. The SiRi pixel can be operated in two modes-the backgate mode (Figure 5B) and frontgate mode (Figure 5C). In the backgate mode, the gate of the control transistor is biased at a fixed frontgate voltage while the SiRi is turned ON or OFF by sweeping the backgate voltage (Figure 5B). In the backgate mode, to turn ON the SiRi pixel, sufficient frontgate voltage needs to be applied such that the MOSFET is first turned ON (Figure 5B). In the frontgate mode, the MOSFET is turned ON or OFF by sweeping the gate of the control transistor while the SiRi is biased at a fixed backgate voltage (Figure $5 \mathrm{C}$ ). In the frontgate mode, to turn ON the SiRi pixel, sufficient backgate voltage needs to be applied such that the $\mathrm{SiRi}$ is first turned ON. In the frontgate mode, the SiRi behaves as a resistor but turned ON/OFF using the backgate voltage (Figure $5 \mathrm{C}$ ).

In the frontgate mode, the gate of the transistor $\left(\mathrm{V}_{\mathrm{G}}\right)$ is swept from -2.5 to $+2.5 \mathrm{~V}$ and an initial bias voltage of $-0.1 \mathrm{~V}$ for P-metal-oxide-semiconductor (PMOS) (or $0.1 \mathrm{~V}$ for N-metal-oxide-semiconductor (NMOS) ) was applied to the drain terminal $\left(\mathrm{V}_{\mathrm{D}}\right)$ while the source terminal $\left(\mathrm{V}_{\mathrm{S}}\right)$ was connected to the ground. The SiRi is turned $\mathrm{ON}$ by the application of a constant bias voltage to the backgate $\left(\mathrm{V}_{\mathrm{BG}}\right)$. In the backgate mode, an initial bias voltage of $-0.1 \mathrm{~V}$ for PMOS (or $0.1 \mathrm{~V}$ for NMOS) was applied 
to the drain terminal $\left(V_{D}\right)$ while the source terminal $\left(V_{S}\right)$ was connected to the ground. Then, a bias voltage of $0 \mathrm{~V}$ was applied to the gate of the control transistor (both NMOS and PMOS), while the backgate was swept from 25 to $-10 \mathrm{~V}$ for P-type and from 0 to $30 \mathrm{~V}$ for N-type SiRi, respectively. In both modes of operation, the fluid gate terminal $\left(\mathrm{V}_{\mathrm{FG}}\right)$ was left open and not connected as these measurements were performed prior to bio functionalization. The influence of substrate voltage bias $\left(\mathrm{V}_{\mathrm{BG}}\right)$ on standalone $\mathrm{N}$ - and P-type transistors was also studied in this work. During the electrical measurements of NMOS transistor, the $\mathrm{V}_{\mathrm{G}}$ was swept from -2.5 to $2.5 \mathrm{~V}$ while keeping the $\mathrm{V}_{\mathrm{S}}$ at $0 \mathrm{~V}$, $\mathrm{V}_{\mathrm{D}}$ at $0.1 \mathrm{~V}$ and stepping $\mathrm{V}_{\mathrm{BG}}(-15,-10,-5,0,5,10,15,20,25$ and $50 \mathrm{~V})$. Similarly, in the case of the PMOS transistor, the $\mathrm{V}_{\mathrm{G}}$ was swept from -2.5 to $2.5 \mathrm{~V}$ while keeping the $\mathrm{V}_{\mathrm{S}}$ at $0 \mathrm{~V}, \mathrm{~V}_{\mathrm{D}}$ at $-0.1 \mathrm{~V}$ and stepping $\mathrm{V}_{\mathrm{BG}}(-50,-25,-20,-15,-10,-5,0,5,10,15 \mathrm{~V})$.

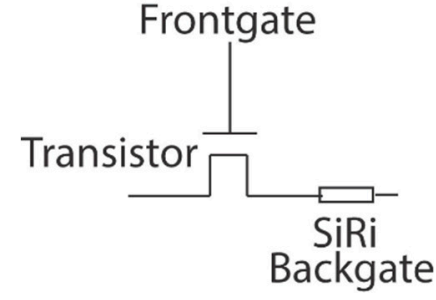

(A) SiRi pixel

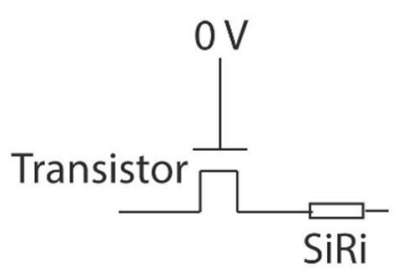

Sweep $-10 \mathrm{~V}$ to $+30 \mathrm{~V}$

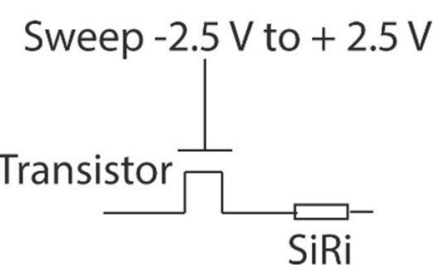

Fixed voltage $=-10 \mathrm{~V}$

Figure 5. (A) The test setup for electrical evaluation of the SiRi pixel sensors in (B) backgate mode where frontgate of the control transistor is fixed at $0 \mathrm{~V}$ while the backgate of the SiRi is swept from -10 to $+30 \mathrm{~V}$ and $(\mathbf{C})$ frontgate mode where the transistor frontgate is swept from -2.5 to $2.5 \mathrm{~V}$ and $\mathrm{SiRi}$ is biased at fixed voltage where it is always ON (-10 V for P-type SiRi).

Table 2 shows the N- and P-type pixels that were studied in this work. The dimensions of the corresponding control transistor and ribbon module in the respective pixel is also shown. Single $\mathrm{N}$-type SiRi of $\mathrm{W}=1 \mu \mathrm{m}$ and $\mathrm{L}=1 \mu \mathrm{m}$ was connected to $\mathrm{N}$-type control transistor of $\mathrm{L}=1 \mu \mathrm{m}$ and $\mathrm{W}=4 \mu \mathrm{m}$ respectively. Single P-type SiRi of $\mathrm{W}=1 \mu \mathrm{m}$ and $\mathrm{L}=1 \mu \mathrm{m}$ was connected to P-type control transistor of $\mathrm{L}=1 \mu \mathrm{m}$ and $\mathrm{W}=4 \mu \mathrm{m}$, respectively. The important performance metrics of the SiRi pixels and transistors, namely the subthreshold slope (SS) and threshold voltage $\left(\mathrm{V}_{\mathrm{TH}}\right)$, were noted from the transfer characteristics. The linear extrapolation method was employed to extract the $\mathrm{V}_{\mathrm{TH}}$ of the SiRi pixels and the transistors.

Table 2. Geometrical characteristics of the SiRi pixel devices studied in this work. The thickness of the SiRi sensors is $20 \mathrm{~nm}$. In a N-type pixel, a N-type transistor of $\mathrm{L}=1 \mu \mathrm{m}$ and $\mathrm{W}=4 \mu \mathrm{m}$ is connected to a N-type SiRi sensor of $\mathrm{L}=1 \mu \mathrm{m}$ and $\mathrm{W}=1 \mu \mathrm{m}$. Similarly, in the P-type pixel, a P-type transistor of $\mathrm{L}=1 \mu \mathrm{m}$ and $\mathrm{W}=4 \mu \mathrm{m}$ is connected to a P-type SiRi sensor of $\mathrm{L}=1 \mu \mathrm{m}$ and $\mathrm{W}=1 \mu \mathrm{m}$.

\begin{tabular}{|c|c|c|c|c|c|c|}
\hline \multirow{2}{*}{ Type of Pixel } & \multirow{2}{*}{ Type of Transistor } & \multicolumn{2}{|c|}{ Transistor Dimensions } & \multirow{2}{*}{ Type of SiRi } & \multicolumn{2}{|c|}{ SiRi Dimensions } \\
\hline & & $\mathrm{L}(\mu \mathrm{m})$ & $W(\mu \mathrm{m})$ & & $\mathrm{L}(\mu \mathrm{m})$ & $W(\mu \mathrm{m})$ \\
\hline $\mathrm{N}$ & $\mathrm{N}$ & 1 & 4 & $\mathrm{~N}$ & 1 & 1 \\
\hline $\mathrm{P}$ & $\mathrm{P}$ & 1 & 4 & $\mathrm{P}$ & 1 & 1 \\
\hline
\end{tabular}

\section{Results and Discussion}

\section{1. $I_{D^{-}} V_{G}$ Transfer Characteristics of $N$ - and P-Type Transistors}

Figure 6 shows the wafer scale $I_{D}-V_{G}$ transfer characteristics (at $V_{B G}=0$ V) of standalone NMOS and PMOS transistors manufactured using the same fabrication process as the SiRi pixels. The NMOS and PMOS transistors have a SS of 60-65 mV/dec. The extracted $V_{\mathrm{TH}}$ for NMOS is in the range from -0.3 to $0.3 \mathrm{~V}$ while the PMOS transistor has $\mathrm{V}_{\mathrm{TH}}$ in the range of -0.9 to $-1.1 \mathrm{~V}$. Figure $7 \mathrm{~A}, \mathrm{~B}$ shows 
the $\mathrm{I}_{\mathrm{D}}-\mathrm{V}_{\mathrm{G}}$ transfer characteristics of a single PMOS and NMOS device manufactured on SOI wafer at different $\mathrm{V}_{\mathrm{BG}}$.

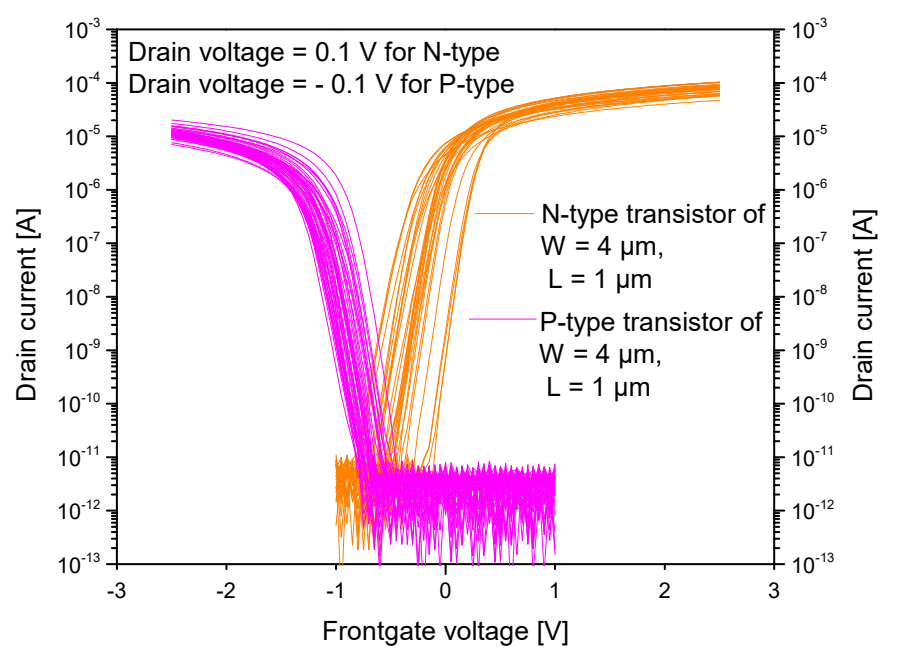

Figure 6. The wafer scale $\mathrm{I}_{\mathrm{D}}-\mathrm{V}_{\mathrm{G}}$ transfer characteristics of standalone NMOS and PMOS transistors manufactured using the same fabrication process as the SiRi pixels. The backgate voltage is set to $0 \mathrm{~V}$ during the measurements.
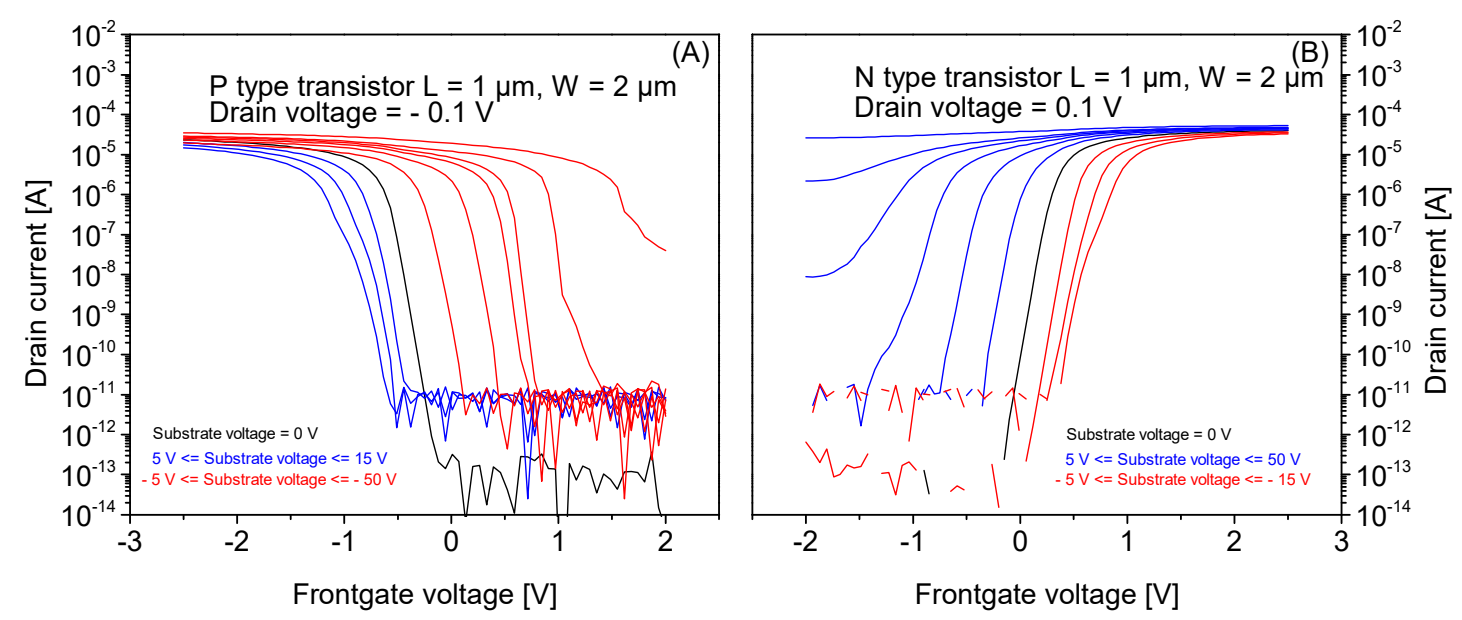

Figure 7. $\mathrm{I}_{\mathrm{D}}-\mathrm{V}_{\mathrm{G}}$ transfer characteristics of standalone (A) P-type and (B) N-type control FET at different $\mathrm{V}_{\mathrm{BG}}$ values. It is clear that application of $\mathrm{V}_{\mathrm{BG}}(>20 \mathrm{~V}$ for $\mathrm{N}$-type and $<-25 \mathrm{~V}$ for P-type) pushes the devices into inversion regime of operation. In addition, the $\mathrm{V}_{\mathrm{TH}}$ and $\mathrm{SS}$ of the devices are impacted by the application of $\mathrm{V}_{\mathrm{BG}}$.

In Figure $7 \mathrm{~A}$, the black color $\mathrm{I}_{\mathrm{D}}-\mathrm{V}_{\mathrm{G}}$ curve of the PMOS is at $\mathrm{V}_{\mathrm{BG}}=0 \mathrm{~V}$. The positive $\mathrm{V}_{\mathrm{BG}}$ values cause the $I_{D}-V_{G}$ transfer characteristics to shift to the left side (blue color) of the $I_{D}-V_{G}$ curve at $\mathrm{V}_{\mathrm{BG}}=0 \mathrm{~V}$ as the back interface is in accumulation. The $\mathrm{V}_{\mathrm{TH}}$ decreases by $\sim 20-25 \mathrm{mV}$ for $1 \mathrm{~V}$ change in $V_{B G}$. The $S S$ is only slightly influenced. The negative $V_{B G}$ values cause the $I_{D}-V_{G}$ transfer characteristics to shift more towards the right side (red color) of the $\mathrm{I}_{\mathrm{D}}-\mathrm{V}_{\mathrm{G}}$ curve at $\mathrm{V}_{\mathrm{BG}}=0 \mathrm{~V}$ as the Si/BOX interface approaches inversion. At $-50 \mathrm{~V} \geq \mathrm{V}_{\mathrm{BG}} \geq-25 \mathrm{~V}$, the frontgate control over the channel is gradually lost causing the increase in SS. As a result, at $V_{B G}$ values $<-25 \mathrm{~V}$, the transistor can no longer be turned off. For $-25 \mathrm{~V} \geq \mathrm{V}_{\mathrm{BG}} \geq-5 \mathrm{~V}$, the $\mathrm{V}_{\mathrm{TH}}$ linearly depends on $\mathrm{V}_{\mathrm{BG}}$ and changes by $\sim 100 \mathrm{mV}$ for $-1 \mathrm{~V}$ change in $\mathrm{V}_{\mathrm{BG}}$.

Similarly, in Figure 7B the black color $\mathrm{I}_{\mathrm{D}}-\mathrm{V}_{\mathrm{G}}$ curve of the NMOS is at $\mathrm{V}_{\mathrm{BG}}=0 \mathrm{~V}$. The negative $\mathrm{V}_{\mathrm{BG}}$ values cause the $\mathrm{I}_{\mathrm{D}}-\mathrm{V}_{\mathrm{G}}$ transfer characteristics to shift to the right side (red color) of the black curve as the back interface is in accumulation. The $\mathrm{V}_{\mathrm{TH}}$ linearly increases by $\sim 20-25 \mathrm{mV}$ for $1 \mathrm{~V}$ change in $V_{B G}$. The $S S$ is only slightly influenced. Whereas the positive $V_{B G}$ values cause the $I_{D}-V_{G}$ transfer 
characteristics to shift more towards the left side (blue color) of the $I_{D}-V_{G}$ curve at $V_{B G}=0 \mathrm{~V}$ as the $\mathrm{Si} / \mathrm{BOX}$ interface approaches inversion. At $50 \mathrm{~V} \leq \mathrm{V}_{\mathrm{BG}} \leq 15 \mathrm{~V}$, the frontgate control over the channel is gradually lost causing the increase in SS. As a result, at $V_{B G}$ values $>25 \mathrm{~V}$, the transistor can no longer be turned off. For $15 \mathrm{~V} \leq \mathrm{V}_{\mathrm{BG}} \leq 5 \mathrm{~V}$, the $\mathrm{V}_{\mathrm{TH}}$ linearly depends on $\mathrm{V}_{\mathrm{BG}}$ and changes by $\sim 100 \mathrm{mV}$ for $1 \mathrm{~V}$ change in $\mathrm{V}_{\mathrm{BG}}$.

Thus, it was found that the backgate voltage strongly influences the SS and $\mathrm{V}_{\mathrm{TH}}$ of the MOSFETs and directly impacts the transfer characteristics. As a result, at $\mathrm{V}_{\mathrm{BG}}$ values $\geq 25 \mathrm{~V}$ for NMOS (or $-25 \mathrm{~V}$ for PMOS), the transistor can no longer be turned off. Thus, it is concluded that, for stable operation of the SiRi pixel, it is important to restrict the $\mathrm{V}_{\mathrm{BG}}$ in voltage range from -10 to $10 \mathrm{~V}$.

\subsection{Backgate Mode of Operation or $I_{D^{-}} V_{B G}$ Transfer Characteristics of $N$ - and P-Type SiRi Pixel Sensors}

Figure $8 \mathrm{~A}, \mathrm{~B}$ shows the wafer scale backgate mode $\mathrm{I}_{\mathrm{D}}-\mathrm{V}_{\mathrm{BG}}$ transfer characteristics of $\mathrm{P}$ - and $\mathrm{N}$-type SiRi pixels $(\mathrm{L}=1 \mu \mathrm{m}$ and $\mathrm{W}=1 \mu \mathrm{m})$, respectively, with frontgate voltage of the control transistor fixed at $0 \mathrm{~V}$.
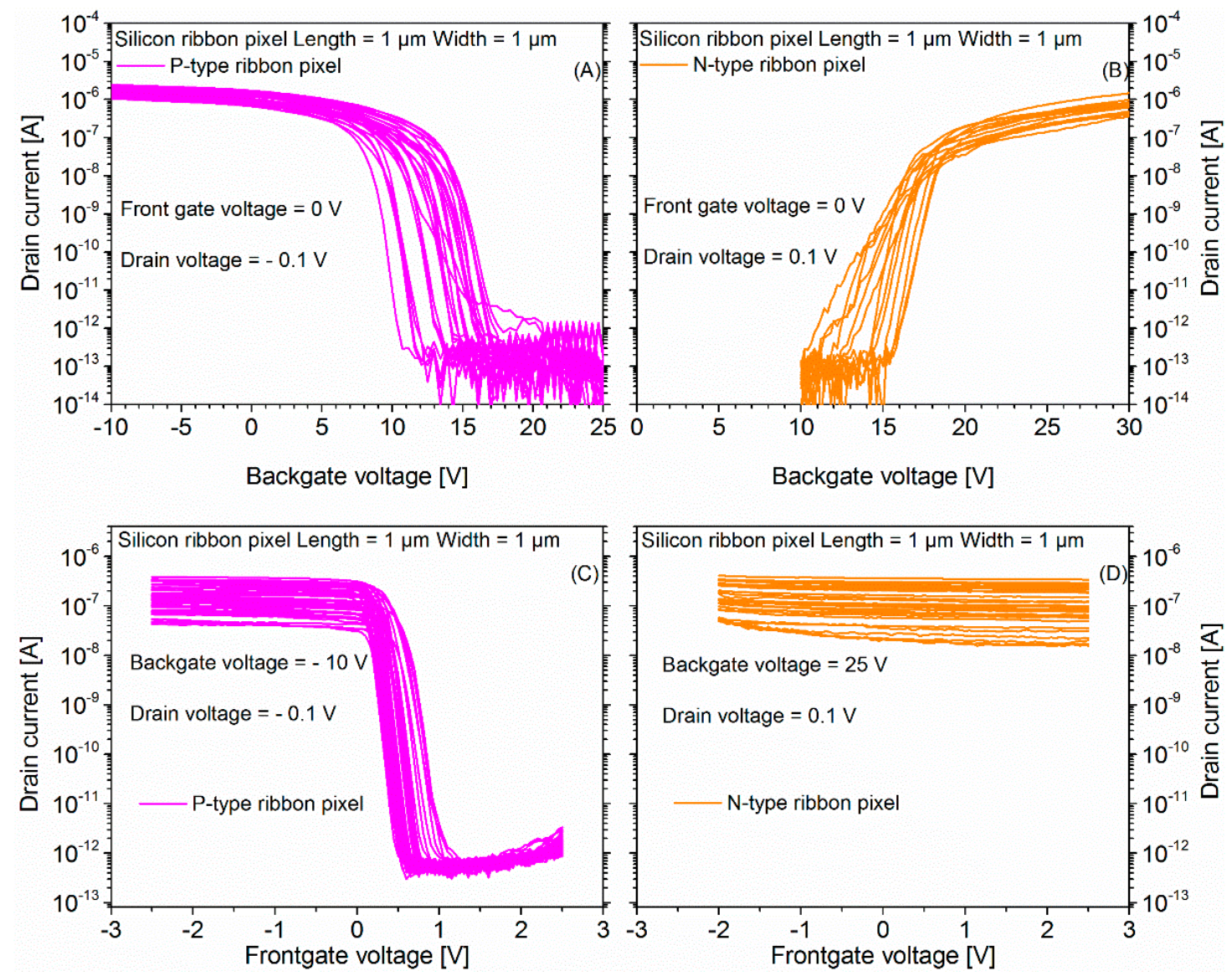

Figure 8. (A) $I_{D}-V_{B G}$ backgate mode transfer characteristics of P-type SiRi pixel sensor; (B) $I_{D}-V_{B G}$ backgate mode transfer characteristics of $\mathrm{N}$-type SiRi pixel sensor; (C) $\mathrm{I}_{\mathrm{D}}-\mathrm{V}_{\mathrm{G}}$ frontgate transfer characteristics of P-type SiRi pixel sensor at $V_{B G}=-10 \mathrm{~V}$; and (D) $I_{D}-V_{G}$ frontgate transfer characteristics of $\mathrm{N}$-type SiRi pixel sensor at $\mathrm{V}_{\mathrm{BG}}=25 \mathrm{~V}$. The N-type pixels cannot turn OFF due to the N-type transistor operating in strong inversion at $\mathrm{V}_{\mathrm{BG}}=25 \mathrm{~V}$ (Figure 7B).

In Figure $8 \mathrm{~B}$, the $\mathrm{N}$-type sensors conduct a current of value $\geq 1 \mathrm{nA}$ from the source to the drain region when $V_{B G} \geq 15 \mathrm{~V}$ while the current values drop to a value of $\leq 1 \mathrm{pA}$ when the $V_{B G}$ is decreased to values lesser than $10 \mathrm{~V}$ confirming that the SiRi pixels exhibit characteristics similar to the N-type MOSFETs. The N-type pixel is turned $\mathrm{ON}$ as long as the control transistor is biased in the inversion region $\left(\mathrm{V}_{\mathrm{G}}=0 \mathrm{~V}\right)$. Similarly, in Figure $8 \mathrm{~A}$, the P-type sensors conduct a current of value $\geq 10 \mathrm{nA}$ 
from the source to the drain region when $\mathrm{V}_{\mathrm{BG}} \leq 10 \mathrm{~V}$ while the current values drop to a value of $\leq 1 \mathrm{pA}$ when the $\mathrm{V}_{\mathrm{BG}}$ is increased to values greater than $15 \mathrm{~V}$ confirming that the SiRi sensors exhibit characteristics similar to the P-type MOSFETs. The P-type pixel is turned ON as long as the control transistor is biased in the inversion region $\left(\mathrm{V}_{\mathrm{G}}=0 \mathrm{~V}\right)$. A SS value of $70-80 \mathrm{mV} / \mathrm{dec}$ and $\mathrm{I}_{\mathrm{ON}} / \mathrm{I}_{\mathrm{OFF}} \geq 10^{6}$ was noted for both $\mathrm{N}$ - and P-type sensors.

The $\mathrm{V}_{\mathrm{TH}}$ of the N-type pixel was found to range from 12.5 to $15.5 \mathrm{~V}$ while the $\mathrm{V}_{\mathrm{TH}}$ of the P-type sensor was found to range from 10 to $15 \mathrm{~V}$. This indicates that the number of charges per unit area in the BOX is $2.2 \times 10^{12} \mathrm{~cm}^{-2}$. These first observations of high $\mathrm{V}_{\mathrm{TH}}$ variations also hint at the importance of the backgate interface between c-Si SiRi sensor/BOX layer.

\subsection{Frontgate Mode of Operation or $I_{D}-V_{G}$ Transfer Characteristics of $N$ - and P-Type SiRi Pixel Sensors}

Figure $8 \mathrm{C}, \mathrm{D}$ shows the wafer scale frontgate mode $\mathrm{I}_{\mathrm{D}}-\mathrm{V}_{\mathrm{G}}$ transfer characteristics of corresponding P- and N-type SiRi pixel devices ( $\mathrm{L}=1 \mu \mathrm{m}$ and $\mathrm{W}=1 \mu \mathrm{m})$, respectively. In Figure $8 \mathrm{C}, \mathrm{D}$, the P-type SiRi pixel was biased with $V_{B G}=-10 \mathrm{~V}$ and N-type SiRi pixel device was biased with $V_{B G}=25 \mathrm{~V}$, respectively. The $\mathrm{I}_{\mathrm{D}}-\mathrm{V}_{\mathrm{G}}$ transfer characteristics of $\mathrm{N}$ - and P-type SiRi pixel devices is similar to the $\mathrm{I}_{\mathrm{D}}-\mathrm{V}_{\mathrm{G}}$ transfer characteristics of $\mathrm{N}$ - and P-type MOSFET devices, respectively. However, in Figure 8B, the N-type SiRi has high $\mathrm{V}_{\mathrm{TH}}$ in backgate mode due to the thick BOX layer. In particular, the N-type $\mathrm{SiRi}$ (Figure $8 \mathrm{~B}$ ) is in the inversion region of operation at $\mathrm{V}_{\mathrm{BG}} \geq 20 \mathrm{~V}$. Thus, to turn $\mathrm{ON}$ the N-type SiRi pixel in the frontgate mode, the SiRi sensor connected at the output should be biased at $V_{B G}$ $\geq 20 \mathrm{~V}$. When the N-type SiRi pixel sensor was biased with a $V_{B G}=25 \mathrm{~V}$, it was observed that the pixel sensor could not be turned OFF (Figure 8D). This behavior can be understood by referring to the influence of $V_{B G}$ on the $I_{D}-V_{G}$ transfer characteristics of N-type transistors that control the SiRi sensor device (Figure 6). It can be noted that $\mathrm{N}$-type standalone transistors have an average $\mathrm{V}_{\mathrm{TH}}$ of $\sim 0 \mathrm{~V}$ and variation of $\pm 0.3 \mathrm{~V}$. Applying a $\mathrm{V}_{\mathrm{BG}}=25 \mathrm{~V}$ to operate the $\mathrm{N}$-type SiRi pixel sensor in the inversion region pushes the $\mathrm{I}_{\mathrm{D}}-\mathrm{V}_{\mathrm{G}}$ transfer characteristics of the $\mathrm{N}$-type control transistor to even stronger inversion region (Figure 7B) where it can no longer be turned OFF. The $\mathrm{V}_{\mathrm{TH}}$ of the N-type transistor shifts further to the left side from its ideal operating condition at $\mathrm{V}_{\mathrm{BG}}=0 \mathrm{~V}$ as it moves towards inversion. In the inversion region, the influence of the $V_{B G}$ on the control transistor is stronger than that of the frontgate voltage $\left(\mathrm{V}_{\mathrm{G}}\right)$. Since the NMOS transistor controls the N-type SiRi pixel, even the N-type pixels can no longer be turned OFF for $\mathrm{V}_{\mathrm{BG}} \geq 25 \mathrm{~V}$.

Similarly, the P-type SiRi pixel (Figure 8A) in backgate mode is in the inversion region of operation at $V_{B G} \leq 10 \mathrm{~V}$. Thus, to turn ON the P-type SiRi pixel, the SiRi sensor connected at the output should be biased at $V_{B G} \leq 10 \mathrm{~V}$. When the P-type SiRi pixel sensor was biased with a $V_{B G}=-10 \mathrm{~V}$, it was observed that the pixel sensor behaves similar to the P-type MOSFETs (Figure 8C). This behavior is contrary to that of $\mathrm{N}$-type SiRi pixel shown in Figure $8 \mathrm{D}$. This can be understood by referring to the influence of $V_{B G}$ on the $I_{D}-V_{G}$ transfer characteristics of P-type transistors that control the SiRi sensor device (Figure 6). In Figure 6, it can be noted that P-type standalone transistors have an average $\mathrm{V}_{\mathrm{TH}}$ of $\sim-1.1 \mathrm{~V}$ and variation of $\pm 0.1 \mathrm{~V}$. Applying a $\mathrm{V}_{\mathrm{BG}}=-10 \mathrm{~V}$ to operate the P-type SiRi pixel sensor in the inversion region pushes the $\mathrm{I}_{\mathrm{D}}-\mathrm{V}_{\mathrm{G}}$ transfer characteristics of the P-type control transistor to strong inversion region (Figure 7A). The $\mathrm{V}_{\mathrm{TH}}$ of the P-type pixel sensors is shifted further to the right side from the $\mathrm{V}_{\mathrm{TH}}$ of the P-type transistors (Figure 8C). Particularly, it can be noted that the $\mathrm{V}_{\mathrm{TH}}$ of the single P-type pixel sensors is $\sim 0.5 \mathrm{~V}$ and variation of $\pm 0.2 \mathrm{~V}$. However, because of operating the P-type pixels at $\mathrm{V}_{\mathrm{BG}}=-10 \mathrm{~V}$, a relatively low value, the P-type transistor can still be turned OFF. In Figure 8C, the P-type pixels exhibit excellent $\mathrm{I}_{\mathrm{ON}} / \mathrm{I}_{\mathrm{OFF}} \geq 10^{6}, \mathrm{SS}$ of $70-80 \mathrm{mV} / \mathrm{dec}$ and $\mathrm{V}_{\mathrm{TH}}$ of $0.5 \mathrm{~V}$ (at $\mathrm{V}_{\mathrm{BG}}=-10 \mathrm{~V}$ ). However, note that the SiRi connected to the PMOS transistor also behaves as a resistor in series with the PMOS transistor. As a result, the P-type SiRi pixels have a flat saturation characteristic of the ON current. Nonetheless, when operating the P-type pixels for DNA detection or bio-experiments, it is expected to work in the subthreshold region of operation where there is exponential dependence of the drain current with respect to frontgate voltage $\left(\mathrm{V}_{\mathrm{G}}\right)$. Hence, the resistance arising due to the SiRi pixel will not influence the detection mechanism. 
Thus, from the results in Figure $8 \mathrm{C}, \mathrm{D}$, it can be concluded that the operating voltage of the SiRi pixel sensors directly depends on the $\mathrm{V}_{\mathrm{TH}}$ of the standalone SiRi sensors connected to the control FET. The quality of the backgate interface between SiRi sensor and BOX plays a key role in determining the operating voltage of the SiRi pixels. If the individual SiRis require larger voltages $(>15 \mathrm{~V})$ to turn $\mathrm{ON}$, then the SiRi pixels cannot be turned OFF as the transistors controlling the SiRi sensors are in strong inversion region of operation. Further, the $\mathrm{V}_{\mathrm{TH}}$ of the individual SiRi sensors depends on the thickness and quality of the BOX layer in the SOI wafer. Since the BOX layer is relatively thick $(145 \mathrm{~nm})$, the voltage required to turn $\mathrm{ON}$ and turn OFF the standalone SiRi sensors is also very high ( $25 \mathrm{~V}$ for $\mathrm{N}$-type and $-10 \mathrm{~V}$ for P-type SiRi). In addition, the fixed charges in the BOX layer will significantly impact the $V_{\mathrm{TH}}$ of the SiRi pixel sensors. A relatively small change of fixed charges of $3 \times 10^{11} \mathrm{~cm}^{-2}$ would induce a $\mathrm{V}_{\mathrm{TH}}$ shift of $2 \mathrm{~V}$ due to the BOX thickness of $145 \mathrm{~nm}$. However, as noted shown in Figure $8 \mathrm{~A}, \mathrm{~B}$, the $\mathrm{V}_{\mathrm{TH}}$ shift is relatively larger $(>15 \mathrm{~V})$ indicating that number of fixed charges in the oxide is of the high order $\sim 2.2 \times 10^{12} \mathrm{~cm}^{-2}$. This issue of $\mathrm{V}_{\mathrm{TH}}$ variation between devices can be overcome by employing SOI wafers with a thinner and high quality BOX layer or by replacing the BOX layer with a metal backgate.

Finally, as shown in Table 3, it is found that the SiRi pixels operating in the frontgate mode of operation exhibit relatively lower $\mathrm{V}_{\mathrm{TH}}$ variation in comparison with SiRi pixels operating in the backgate mode. Particularly, the $\mathrm{V}_{\mathrm{TH}}$ of P-type pixel in the backgate mode operation was found to range from 10 to $15 \mathrm{~V}$ while it was reduced to a $\mathrm{V}_{\mathrm{TH}}$ variation of just 0.3 to $0.7 \mathrm{~V}$ in the frontgate mode of operation. The reduction of the $\mathrm{V}_{\mathrm{TH}}$ in the frontgate mode of operation is due to employing a PMOS transistor to control the SiRi. It can be seen in Figures 6 and $8 \mathrm{C}$ that the $\mathrm{V}_{\mathrm{TH}}$ of the P-type SiRi pixel follows the same $\mathrm{V}_{\mathrm{TH}}$ variation of its respective control P-type transistor. Similarly, in Table 3, the P-type SiRi pixels operating in the frontgate mode of operation exhibit relatively larger $\mathrm{I}_{\mathrm{ON}}$ variation $\left(4 \times 10^{-7}\right.$ to $\left.3 \times 10^{-6} \mathrm{~A}\right)$ in comparison with SiRi pixels operating in the backgate mode $\left(10^{-6}\right.$ to $\left.2.5 \times 10^{-6} \mathrm{~A}\right)$. We speculate this to arise on account of process variations in the channel resistance of the P-type SiRi that is connected to the P-type control transistor.

Table 3. A comparative study of the variation of $\mathrm{V}_{\mathrm{TH}}$ and $\mathrm{I}_{\mathrm{ON}}$ in the P-type SiRi pixel device in the backgate and frontgate mode of operation.

\begin{tabular}{ccc}
\hline Electrical Parameter & $\begin{array}{c}\text { P-Type SiRi Pixel } \\
\text { (Backgate Mode) }\end{array}$ & $\begin{array}{c}\text { P-Type SiRi Pixel } \\
\text { (Frontgate Mode) }\end{array}$ \\
\hline $\mathrm{V}_{\mathrm{TH}}$ variation $(\mathrm{V})$ & 10 to 15 & 0.3 to 0.7 \\
$\mathrm{I}_{\mathrm{ON}}$ variation $(\mathrm{A})$ & $1 \times 10^{-6}$ to $2.5 \times 10^{-6}$ & $4 \times 10^{-7}$ to $3 \times 10^{-6}$ \\
\hline
\end{tabular}

\subsection{Influence of Backgate Voltage on the SiRi Pixel Sensors in Frontgate Mode of Operation}

The mechanism of tuning the $\mathrm{V}_{\mathrm{TH}}$ of the SiRi pixel by using the backgate bias can be exploited to match with the operating voltage of the control CMOS circuits. Therefore, we studied the influence of $V_{B G}$ on the $N$ - and P-type pixels in the frontgate mode operation. Figure $9 A$ shows the $I_{D}-V_{G}$ frontgate transfer characteristics of a single P-type SiRi pixel device of $W=1 \mu \mathrm{m}$ and $\mathrm{L}=1 \mu \mathrm{m}$ at different $\mathrm{V}_{\mathrm{BG}}$. A systematic $\mathrm{V}_{\mathrm{TH}}$ shift of $\sim 40 \mathrm{mV}$ is observed for $1 \mathrm{~V}$ change in $\mathrm{V}_{\mathrm{BG}}$. The $\mathrm{I}_{\mathrm{D}}$ of the pixel also increases by $\sim 3-8 \mathrm{nA}$ for $1 \mathrm{~V}$ change in $\mathrm{V}_{\mathrm{BG}}$. Figure $9 \mathrm{~B}$ shows the $\mathrm{I}_{\mathrm{D}}-\mathrm{V}_{\mathrm{G}}$ frontgate transfer characteristics of a single $\mathrm{N}$-type SiRi pixel device of $\mathrm{W}=1 \mu \mathrm{m}$ and $\mathrm{L}=1 \mu \mathrm{m}$ at different $\mathrm{V}_{\mathrm{BG}}$. Since the controlling NMOS transistor is in strong inversion region for $20 \mathrm{~V} \leq \mathrm{V}_{\mathrm{BG}} \leq 25 \mathrm{~V}$, the N-type SiRi cannot be turned OFF.

In Figure $8 \mathrm{~A}$, in the backgate mode, P-type SiRi pixel is operating in the inversion region at $V_{B G}=-10 \mathrm{~V}$. Further, in Figure 8C, the P-type pixels can be switched ON by applying a $V_{B G}=-10 \mathrm{~V}$ to the SiRi connected at the output. However, in Figure $9 \mathrm{~A}$, i for $-1 \mathrm{~V} \geq \mathrm{V}_{\mathrm{BG}} \geq 0 \mathrm{~V}$, the P-type pixels are in OFF state as the P-type SiRi connected at the output of the pixel is in OFF state. For $-4 \mathrm{~V} \geq \mathrm{V}_{\mathrm{BG}} \geq-2 \mathrm{~V}$, the P-type SiRi at the output of the pixel is in the weak inversion region. Thus, the $\mathrm{I}_{\mathrm{D}}$ of the P-type pixel is lower $(50 \mathrm{nA})$. At the same time, the application of a $\mathrm{V}_{\mathrm{BG}}=-4 \mathrm{~V}$ 
causes the $\mathrm{V}_{\mathrm{TH}}$ of the PMOS control transistor to shift towards the right side as the transistor moves towards strong inversion (Figure $7 \mathrm{~A}$ ).
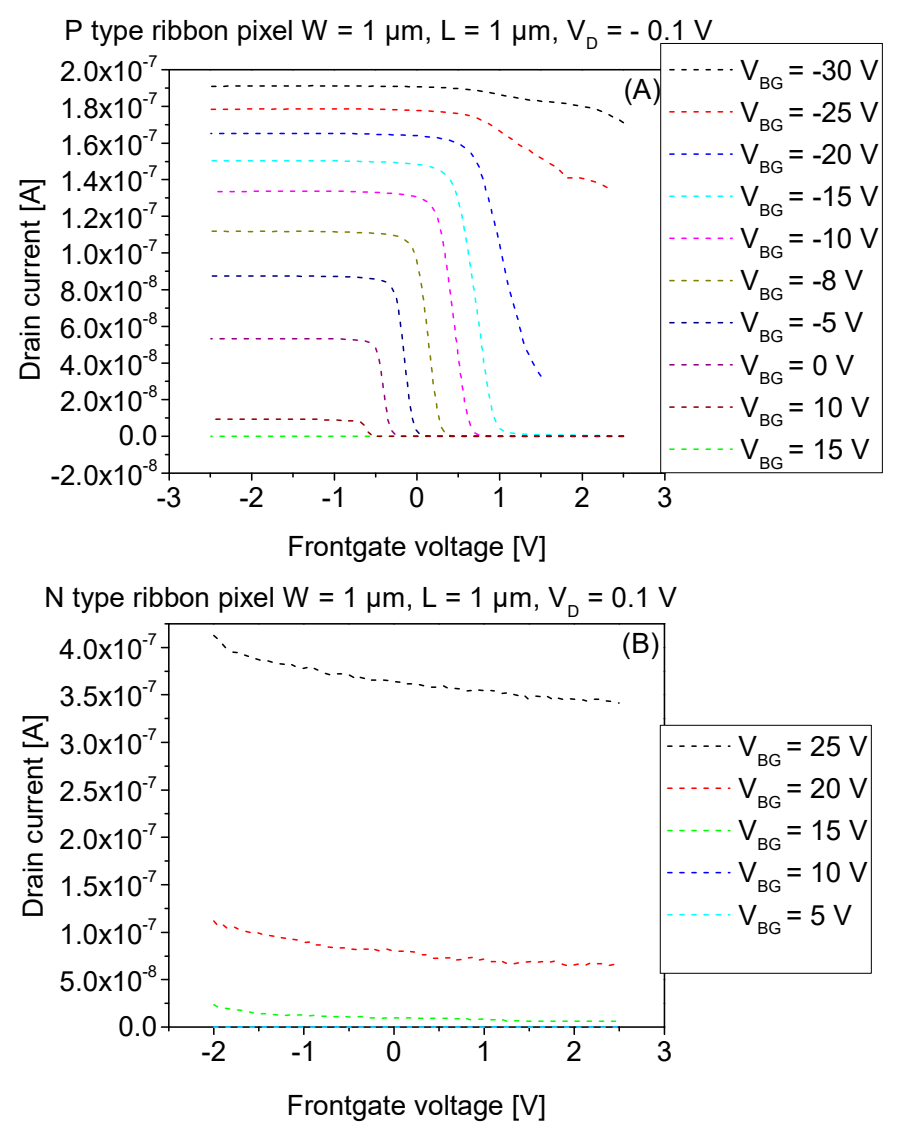

Figure 9. $I_{D}-V_{G}$ frontgate mode transfer characteristics of (A) P-type and (B) N-type SiRi pixel at different $V_{B G}$ values. It is observed that application of $V_{B G}$ causes the modulation of $\mathrm{I}_{\mathrm{D}}, \mathrm{V}_{\mathrm{TH}}$ and $S S$ of the P-type pixel devices (A). The N-type pixel devices (B) cannot be turned OFF even by applying $5 \mathrm{~V} \leq \mathrm{V}_{\mathrm{BG}} \leq 25 \mathrm{~V}$ because the standalone $\mathrm{N}$-type SiRi sensor switches $\mathrm{ON}$ at $\mathrm{V}_{\mathrm{BG}} \geq 25 \mathrm{~V}$ (Figure 8B). Simultaneously, at $\mathrm{V}_{\mathrm{BG}} \geq 20 \mathrm{~V}$, the N-type control FET moves to strong inversion (Figure 7B) where it can no longer be turned OFF. As a result, the pixel that is controlled by the N-type FET is also not turned OFF.

A further increase of the $V_{B G}\left(-20 \mathrm{~V} \geq V_{B G} \geq-6 \mathrm{~V}\right)$, causes the P-type SiRi at the output of the pixel to move towards the strong inversion. As a result, the $\mathrm{I}_{\mathrm{D}}$ of the P-type pixel also increases $80 \mathrm{nA}-0.16 \mu \mathrm{A}$ (Figure 9A). Concurrently, this increase in $\mathrm{V}_{\mathrm{BG}}\left(-20 \mathrm{~V} \geq \mathrm{V}_{\mathrm{BG}} \geq-6 \mathrm{~V}\right)$ causes the $\mathrm{V}_{\mathrm{TH}}$ of the PMOS control transistor to shift further towards the right side as the transistor moves towards even stronger inversion (Figure 7A). Eventually, at $\mathrm{V}_{\mathrm{BG}} \leq-20 \mathrm{~V}$, the control PMOS transistor can no longer be turned OFF. Since the P-type SiRi pixel is controlled by the PMOS transistor, even the P-type pixels can no longer be turned OFF for $\mathrm{V}_{\mathrm{BG}} \leq-20 \mathrm{~V}$.

Note that, in Figure $8 \mathrm{C}, \mathrm{D}$, the frontgate voltage $\left(\mathrm{V}_{\mathrm{G}}\right)$ of the $\mathrm{N}$ - and P-type pixels is swept from -2.5 to $2.5 \mathrm{~V}$. Further increase of the frontgate voltage than the aforementioned range ( -2.5 to $2.5 \mathrm{~V})$ will lead to the dielectric breakdown $\left(4 \mathrm{~nm} \mathrm{SiO}_{2}\right)$ in the control transistors. Thus, from this dependence of the $\mathrm{N}$ - and P-type SiRi pixels (Figures $8 \mathrm{D}$ and $9 \mathrm{~A}$ ) on $\mathrm{V}_{\mathrm{BG}}$, it can be concluded that it is important to restrict the $\mathrm{V}_{\mathrm{TH}}$ of the $\mathrm{N}$ - and P-type SiRi connected at the control FET to low values (5 V $\leq \mathrm{V}_{\mathrm{BG}} \leq 10 \mathrm{~V}$ for $\mathrm{N}$-type and $-5 \mathrm{~V} \geq \mathrm{V}_{\mathrm{BG}} \geq-10 \mathrm{~V}$ for P-type sensors). As long as the $\mathrm{V}_{\mathrm{BG}}$ value required to turn $\mathrm{ON}$ the standalone SiRi sensors is within the operating bounds ( -2.5 to $2.5 \mathrm{~V}$ ) of the transistor controlling them, then the SiRi pixel sensors can be switched ON or OFF. Otherwise, the large $V_{B G}$ value applied to turn ON the SiRi sensors, will push the controlling transistor in the SiRi pixel device, towards stronger 
inversion region of operation where the influence of backgate voltage $\left(V_{B G}\right)$ is greater than that of the frontgate $\left(V_{G}\right)$. As a result, the SiRi pixel devices cease to switch OFF. The thickness and quality of the backgate interface or particularly BOX layer in this study will also strongly influence the $V_{B G}$ required to bias the SiRi sensors.

\section{Conclusions}

In this paper, the monolithic integration of SiRi sensor with CMOS has been realized using a novel pixel-based LOC architecture. A single pixel sensor comprised of a control MOSFET, an on-chip fluid-gate and a SiRi sensor connected at its output. In particular, single N- and P-type SiRi sensors of dimensions $\mathrm{W}=1 \mu \mathrm{m}$ and $\mathrm{L}=1 \mu \mathrm{m}$ were connected with $\mathrm{N}$ - and P-type CMOS transistors of $\mathrm{W}=4 \mu \mathrm{m}$ and $\mathrm{L}=1 \mu \mathrm{m}$ respectively. The top-down method of fabrication was exploited to manufacture the SiRi pixels. Wafer scale integration was exposed on $100 \mathrm{~mm}$ SOI substrate using the CMOS industry grade materials and tools.

Furthermore, we demonstrated the first electrical results of the pixel design for both $\mathrm{N}$ - and P-type SiRi pixels in two different modes: (a) the backgate mode; and (b) the frontgate mode. From the $\mathrm{I}_{\mathrm{D}}-\mathrm{V}_{\mathrm{BG}}$ characteristics in the backgate mode, it is found that the $\mathrm{N}$ - and P-type pixels exhibit similar characteristics to that of $\mathrm{N}$ - and P-type MOSFETs, respectively, with a SS of $70-80 \mathrm{mV} / \mathrm{dec}$ and $\mathrm{I}_{\mathrm{ON}} / \mathrm{I}_{\mathrm{OFF}}$ $\geq 10^{6}$. The $\mathrm{V}_{\mathrm{TH}}$ variation of $12.5-15.5 \mathrm{~V}$ for $\mathrm{N}$-type pixel and 10-15 V for P-type pixel was also noted in the backgate mode of operation. Likewise, the $I_{D}-V_{G}$ frontgate mode transfer characteristics of $\mathrm{N}$ - and P-type SiRi pixel devices were noted to be similar to the $\mathrm{I}_{\mathrm{D}}-\mathrm{V}_{\mathrm{G}}$ transfer characteristics of $\mathrm{N}$ and P-type MOSFETs, respectively. However, in the frontgate operation, a strong dependence was observed on the quality of the SiRi backgate interface. Since the number of charges in the BOX was high $\left(2.2 \times 10^{12} \mathrm{~cm}^{-2}\right)$, it caused a large $\mathrm{V}_{\mathrm{TH}}$ shift in SiRi sensors, which in turn impacted the frontgate mode of operation. It was revealed that individual SiRis require larger voltages $(>15 \mathrm{~V})$ to turn ON, and then the SiRi pixels cannot be turned OFF as the transistors controlling the SiRi sensors are in strong inversion region of operation. Particularly, the N-type pixels cannot be turned OFF due to the control NMOS operating in the strong inversion regime. This is because of large $\mathrm{V}_{\mathrm{BG}}$ application to turn $\mathrm{ON}$ the SiRi sensor $\left(\mathrm{V}_{\mathrm{BG}} \geq 25 \mathrm{~V}\right)$. Conversely, the P-type SiRi sensors in the frontgate mode do not require large $\mathrm{V}_{\mathrm{BG}}$ to switch $\mathrm{ON}$. Thus, the P-type pixels exhibit excellent $\mathrm{I}_{\mathrm{ON}} / \mathrm{I}_{\mathrm{OFF}} \geq 10^{6}$, SS of $70-80 \mathrm{mV} / \mathrm{dec}$ and $\mathrm{V}_{\mathrm{TH}}$ of $0.5 \mathrm{~V}\left(\right.$ at $\left.\mathrm{V}_{\mathrm{BG}}=-10 \mathrm{~V}\right)$.

Lastly, we show the influence of different $V_{B G}$ bias on the $I_{D}-V_{G}$ frontgate transfer characteristics of a single P-type SiRi pixel device. A systematic $V_{T H}$ shift of $\sim 40 \mathrm{mV}$ is observed for $1 \mathrm{~V}$ change in $\mathrm{V}_{\mathrm{BG}}$. The $\mathrm{I}_{\mathrm{D}}$ of the pixel also increases by $\sim 3-8 \mathrm{nA}$ for $1 \mathrm{~V}$ change in $\mathrm{V}_{\mathrm{BG}}$. The tuning of the $\mathrm{V}_{\mathrm{TH}}$ of the SiRi pixel by using the backgate bias will be useful to match with the operating voltage of the control CMOS circuits. Indeed, the novel pixel based design and promising transfer characteristics of SiRi pixels addresses the key area of selectively accessing SiRi sensors using CMOS transistors. Thus, the concept of monolithic integration of SiRi sensors with CMOS technology is successfully demonstrated.

Author Contributions: Conceptualization, G.J.; Formal analysis, G.J. and P.-E.H.; Funding acquisition, P.-E.H. and M.Ö.; Investigation, G.J.; Methodology, G.J. and P.-E.H.; Project administration, P.-E.H. and M.Ö.; Resources, P.-E.H.; Supervision, P.-E.H. and M.Ö.; Visualization, G.J.; Writing-original draft, G.J.; and Writing-review and editing, P.-E.H. and M.Ö.

Funding: This work was supported by the Nanonets2Sense project fund from by the European Horizon 2020 Program under grant agreement 688329. MyFab, the Swedish national research infrastructure for micro- and nanofabrication, is acknowledged for their contribution.

Conflicts of Interest: The authors declare no competing financial interests.

\section{References}

1. Zhang, G.-J.; Zhang, L.; Huang, M.J.; Luo, Z.H.H.; Tay, G.K.I.; Lim, E.-J.A.; Kang, T.G.; Chen, Y. Silicon nanowire biosensor for highly sensitive and rapid detection of Dengue virus. Sens. Actuators B Chem. 2010, 146, 138-144. [CrossRef] 
2. Lee, J.; Lee, J.M.; Lee, J.H.; Lee, W.H.; Uhm, M.; Park, B.G.; Kim, D.M.; Jeong, Y.J.; Kim, D.H. Complementary silicon nanowire hydrogen ion sensor with high sensitivity and voltage output. IEEE Electron Device Lett. 2012, 33, 1768-1770. [CrossRef]

3. Park, I.; Li, Z.; Pisano, A.P.; Williams, R.S. Top-down fabricated silicon nanowire sensors for real-time chemical detection. Nanotechnology 2010, 21, 15501. [CrossRef] [PubMed]

4. Yoo, S.K.; Yang, S.; Lee, J.H. Hydrogen iIon sensing using schottky contacted silicon nanowire FETs. IEEE Trans. Nanotechnol. 2008, 7, 745-748. [CrossRef]

5. Nguyen, T.T.T.; Legallais, M.; Morisot, F.; Cazimajou, T.; Mouis, M.; Salem, B.; Stambouli, V.; Ternon, C. On the development of label-free DNA sensor using silicon nanonet field-effect transistors. Proceedings 2017, 1, 312. [CrossRef]

6. Kim, A.; Ah, C.S.; Yu, H.Y.; Yang, J.-H.; Baek, I.-B.; Ahn, C.-G.; Park, C.W.; Jun, M.S.; Lee, S. Ultrasensitive, label-free, and real-time immunodetection using silicon field-effect transistors. Appl. Phys. Lett. 2007, 91, 103901. [CrossRef]

7. Chiang, P.L.; Chou, T.C.; Wu, T.H.; Li, C.C.; Liao, C.D.; Lin, J.Y.; Tsai, M.H.; Tsai, C.C.; Sun, C.J.; Wang, C.H.; et al. Nanowire transistor-based ultrasensitive virus detection with reversible surface functionalization. Chem. Asian J. 2012, 7, 2073-2079. [CrossRef] [PubMed]

8. Chen, Y.; Wang, X.; Erramilli, S.; Mohanty, P. Silicon-based nanoelectronic field-effect pH sensor with local gate control. Appl. Phys. Lett. 2006, 89, 223512. [CrossRef]

9. Tarasov, A.; Wipf, M.; Stoop, R.L.; Bedner, K.; Fu, W.; Guzenko, V.A.; Knopfmacher, O.; Calame, M.; Schönenberger, C. Understanding the electrolyte background for biochemical sensing with ion-sensitive field-effect transistors. ACS Nano 2012, 6, 9291-9298. [CrossRef] [PubMed]

10. Shaya, O.; Shaked, M.; Doron, A.; Cohen, A.; Levy, I.; Rosenwaks, Y. Distinguishing between dipoles and field effects in molecular gated transistors. Appl. Phys. Lett. 2008, 93, 43509. [CrossRef]

11. Jayakumar, G.; Legallais, M.; Hellström, P.-E.; Mouis, M.; P-Paintrand, I.; Stambouli, V.; Ternon, C.; Östling, M. Wafer-scale $\mathrm{HfO}_{2}$ encapsulated silicon nanowire field effect transistor for efficient label-free DNA hybridization detection in dry environment, Unpublished work. Nanotechnology 2018, under review.

12. Lee, J.; Jang, J.; Choi, B.; Yoon, J.; Kim, J.-Y.; Choi, Y.-K.; Kim, D.M.; Kim, D.H.; Choi, S.-J. A highly responsive silicon nanowire/amplifier MOSFET hybrid biosensor. Sci. Rep. 2015, 5, 12286. [CrossRef] [PubMed]

13. El Gamal, A.; Eltoukhy, H. CMOS image sensors. IEEE Circuits Devices Mag. 2005, 21, 6-20. [CrossRef]

14. Jayakumar, G.; Asadollahi, A.; Hellström, P.-E.; Garidis, K.; Östling, M. Silicon nanowires integrated with CMOS circuits for biosensing application. Solid State. Electron. 2014, 98, 26-31. [CrossRef]

15. Curreli, M.; Ishikawa, F.N.; Cote, R.J.; Thompson, M.E. Real-time label-free detection of biological entities using nanowire-based FETs. IEEE Trans. Nanotechnol. 2008, 7, 651-667. [CrossRef]

16. Knopfmacher, O. Sensing with Silicon Nanowire Field-Effect Transistors. 2011. Available online: http: / / edoc.unibas.ch/1351/1/Diss_Knopfmacher.pdf (accessed on 18 September 2015).

17. Rigante, S. High-K dielectric FinFETs on Si-bulk for ionic and biological sensing integrated circuits. EPFL 2014, 1, 18-19. [CrossRef]

18. Legallais, M. Design, Study and Modeling of a New Generation of Silicon Nanowire Transistors for Biosensing Applications, Université Grenoble Alpes, 2017. Available online: https://tel.archives-ouvertes. $\mathrm{fr} /$ tel-01745520 (accessed on 25 May 2018).

19. Zhang, G.-J.; Huang, M.J.; Luo, Z.H.H.; Tay, G.K.I.; Lim, E.-J.A.; Liu, E.T.; Thomsen, J.S. Highly sensitive and reversible silicon nanowire biosensor to study nuclear hormone receptor protein and response element DNA interactions. Biosens. Bioelectron. 2010, 26, 365-370. [CrossRef] [PubMed]

20. Hellström, P.-E.; Jayakumar, G.; Östling, M. Integration of silicon nanowires with CMOS. Beyond-CMOS Nanodevices 2014, 1, 65-72. [CrossRef]

(C) 2018 by the authors. Licensee MDPI, Basel, Switzerland. This article is an open access article distributed under the terms and conditions of the Creative Commons Attribution (CC BY) license (http://creativecommons.org/licenses/by/4.0/). 